\title{
Relating Creativity and Imagination: Studying Collective Models of Creative Collaboration
}

\author{
Raffaella Perrone* \\ Managing Director of Design AREA in IED Barcelona School of Design, Spain \\ *Corresponding author: lellaperrone@hotmail.com
}

Received September 14, 2014; Revised October 05, 2014; Accepted October 30, 2014

\begin{abstract}
This paper focuses on collective creativity in process design. The purpose of this contribution is to spotlight the factors that play a role in defining students' creativity, with a special emphasis on the relationship between creativity and imagination, studying collective models of creative collaboration. We present two case studies in which we have specifically worked with groups of students to create a collective project proposing methodologies of experimental work. In both cases, the collective creation favoured the development of individual creativity.
\end{abstract}

Keywords: creativity, imagination, co-creation, process design

Cite This Article: Raffaella Perrone, "Relating Creativity and Imagination: Studying Collective Models of Creative Collaboration.” American Journal of Educational Research, vol. 2, no. 10 (2014): 975-980. doi: 10.12691/education-2-10-19.

\section{Introduction}

Technical schools and universities train not only future professionals but also individuals and citizens. Therefore, design schools in particular must become more deeply committed to the education of future designers who will shape our everyday environment. The educational system must constantly undergo change and must continuously rationalise the educational models in order to align them with the times [1].

It is a fact that students - using the term very loosely, starting from when they enter school as young children no longer need to go to school to learn. Today knowledge is global and can be accessed from thousands of channels that are much more dynamic and interesting than the traditional encyclopaedic culture. Schools must therefore focus on the ways people learn and on developing competencies related to training the mind to process and synthesise information and generate innovative ideas. At a design school, the emphasis should be on "lateral thinking” [2] and/or “divergent thinking” [3], which constantly strives to break the moulds of experience.

\section{Theoretical Context}

David A. Kolb’s book about experimental learning [4], was an attempt to assess individual learning styles and help individuals identify the way they learn from experience. His famous learning cycle is based partly on learning concrete experiences and adding reflection, conceptualisation and action. This model of learning (e.g. Figure 1) is particularly successful at linking theory and practice, and especially interesting for my study.

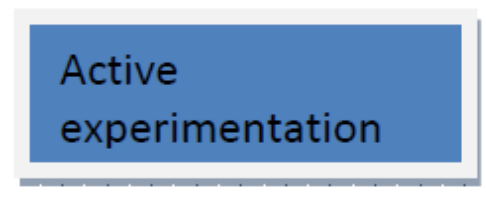

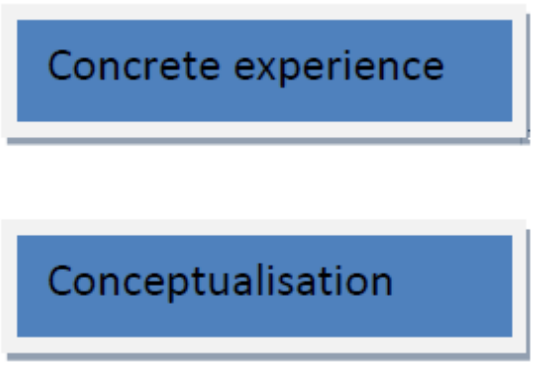

Figure 1. David A. Kolb's learning cycle

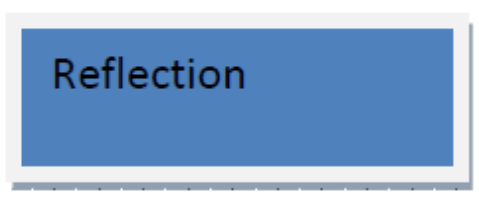

I would like to stress the need to reflect on this topic in the context of the Spanish educational system, because at the university level we suffer from the results of an academic curriculum grounded on rote, behavioural learning. Consequently, at project-based universities we must focus on a more collaborative, dynamic and experiential kind of learning.

Design programmes in Spain have only been recognised as Bachelor's degrees in the past five years. ELISAVA, founded in 1961, was the first Spanish design 
school and one of the first schools to adapt its educational system to the European Higher Education Area. Since 1997, the school has offered a blend of different yet complementary programmes and careers, including design programmes with specialisations in graphic design, industrial design and interior design, and design engineering. They all benefit by sharing faculty, classrooms and students.

ELISAVA's international faculty includes professionals from various backgrounds, such as designers, architects, engineers, artists, anthropologists, sociologists, art critics, economists and entrepreneurs.

In design teaching and for many decades, theories have been proposed about design project methods and methodologies. However, only in recent years have theoretical approaches to creativity and the creative process been proposed and implemented in academic curricula, or as working methods (co-creation). Creativity, thus, has become an area of focus of research, with important implications on the design discipline.

\subsection{Defining Creativity and Imagination}

In order to delimit the theoretical framework of this study, I will define the concepts of creativity and imagination viewed from the discipline of design. If we had to trace back the origin of these words, the sequence in which they appear would have to be reversed (imagination- creativity). It would also become clear that for many years they belonged exclusively to the realm of the history of philosophy, as psychology only started to take an interest in them in the modern age.

Early on, philosophical speculation on these terms was aimed at justifying and understanding artistic creation. It is to philosophy we owe the first distinction between imagination, as the "faculty of producing the perception of what is sensibly absent", and fantasy, as a facultas fingendi which consists of "producing the image of something that has never been perceived by the senses by dividing and composing images.” [5]

By the time, cognitive psychology began to take an interest in imagination and fantasy, the two terms were no longer separated by a conceptual distance. In 1901, Théodule Ribot spoke about “creative imagination”, and in $1930 \mathrm{~L}$. S. Vygotoskij finally recognised in all humans a shared "creative aptitude" whose differences are particularly evidenced as a product of social and cultural factors.

In 1968, Arthur J. Cropley made creativity synonymous with "divergent thinking" that is capable of constantly breaking down schemas and stereotypes based on experience.

In 1973 Rodari wrote:

"A mind that always works, that is always willing to question, to discover problems where others find satisfactory answers (...), that rejects the codified, that manipulates objects and concepts without letting itself be inhibited by conformity, that is a creative mind.”[6]

Finally, given these premises, Bruno Munari [7] classified and defined these terms:

CREATIVITY - Everything that did not exist before but can be realised globally. In the field of design, creativity serves an aesthetic purpose and meets social, economic, human and psychological needs.
IMAGINATION - This is the ability to visualise ideas. Imagination makes visible what fantasy, creativity and invention dream up. Imagination can visualise things that already exist and is not necessarily creative.

Bearing these definitions in mind, I believe that it is important to include Margaret A. Boden's description of the concept of creativity:

"Creativity is the ability to come up with ideas or artifacts that are new, surprising and valuable... As these very diverse examples suggest, creativity enters into virtually every aspect of life. It's not a special faculty but an aspect of human intelligence in general: in other words, it's grounded in everyday abilities such as conceptual thinking, perception, memory, and reflective self-criticism. So it isn't confined to a tiny elite: every one of us is creative, to a degree." [8].

Boden's definition further clarifies that what matters is not "who thought of the idea first" but "how did that person manage to come up with it, given that they had never thought of it before?" Boden thus distinguishes between psychological creativity (P-creativity) and historical creativity (H-creativity). However, these definitions apply to individual creativity.

In his book [9], Roberto Bolullo clearly distinguishes between individual creativity, group creativity and cocreation, explaining the various levels and what each of them implies. Group creativity is what leads each group component to share with other group members their skills and knowledge. It also boosts creative energy which in turn fuels individual energies.

\section{Hypothesis}

The proposed topic of this paper partly dovetails with my work as a coordinator and my role at the Projects Department of ELISAVA. This enables me to share some of the methodological questions that the teaching team and I are examining with regard to how to stimulate, nurture and train our students in individual and collective creativity.

Our first hypothesis is that the more we stimulate collective creativity, the more we nurture individual creative energy. Therefore, our pedagogical goal should be to stimulate creativity and lateral thinking with concrete experiences of creative collaboration.

Youngsters nowadays are used to being connected to each other, sharing their experiences, feelings and their own personality, which can at times seem alien to us as professors.

As teachers and trainers of future professionals who are increasingly interconnected through social networks and online interaction, we will have to educate and hone our students' minds in group creativity skills, developing competencies and personal aptitudes that are in line with this type of creative process.

Our second hypothesis is that with age, students tend to acquire mental stereotypes that restrict the creativity model. Age influences models of individual and collective creativity. In general, children are more creative and collaborative because they are not yet conditioned by mental stereotypes. Children, especially pre-schoolers, don't fear having their ideas assessed or making mistakes. 
So, schools should promote collective creativity models detached from stereotypes because it's easier for students to discover their creative potential when the outcome is collective. Students are not worried about a comparative evaluation with others and they feel freer.

We have two interesting cases that are worth sharing to demonstrate our hypothesis. I believe that in order to be consistent with our own premises, we can never reach simplistic conclusions.

\section{Case Studies}

Below I present two case studies developed as extraacademic projects which illustrate our two working hypothesis.

The first project was commissioned by Ericsson and the second was a self-commission by ELISAVA to put students' creative capacity to the test. Both are interventions involving graphics applied to ephemeral spaces.

\subsection{Case Study 1}

In March 2011 ELISAVA was contacted by an agency to recruit a group of students as "illustrators" for the Ericsson booth at the Mobile World Congress Fair, an interesting co-creation project.

Six third-year students created a "Living wall" in real time reflecting the network society of the future, according to the briefing proposed by Ericsson. We suggested that students were not mere executors but could work according to a common strategic approach that would ensure a consistent result in the large backdrop $(2 \mathrm{x}$ $6 \mathrm{~m}$ ), with the assistance of tutor Chema Longobardo.

This mural was built during the four-day exhibition, and the students interacted with participants of the exhibition in a co-creation process giving us input and opinions that we later tried to depict on the canvas.

The project was divided into two main stages.

1. Brainstorming and concept generation, during one workshop day in ELISAVA to define graphics references and possible techniques to use.

2. Developing sketches and layout of the final art mural at MWC Fair.

The students developed this second phase drawing in real scale, step by step. The challenge was to get something graphically impressive and powerful, limited by improvisation, because there was no possibility to change or rectify.

The project team decided to place a hand in the middle of the wall, as a symbol of the connections between people and the idea of the internet network, and the rest of the wall surface was structured in the following phases:

- List of concepts. Some students wrote in a notebook the proposed ideas from fair visitors, and sketched iconic elements to illustrate these ideas.

- Translating ideas into large drawings. Other students reproduced the small sketches to real-scale size using pencils and pens (e.g. Figure 2a, 2b).

- Adding lettering. Other students added concepts treated with a special typography (e.g. Figure 3).

- Adding colour. When they finished the layout illustration, they added colour according to an established chromatic palette (e.g. Figure 4a, 4b).

- Adding details. In the final phase students retouched and completed details (e.g. Figure 5a, 5b).

In this case, the goal was to apply their imagination to illustrate other people's ideas. Despite the great diversity of proposals offered and the heterogeneity of the team, the results were truly amazing (e.g. Figure 6). (http://vimeo.com/59671073).

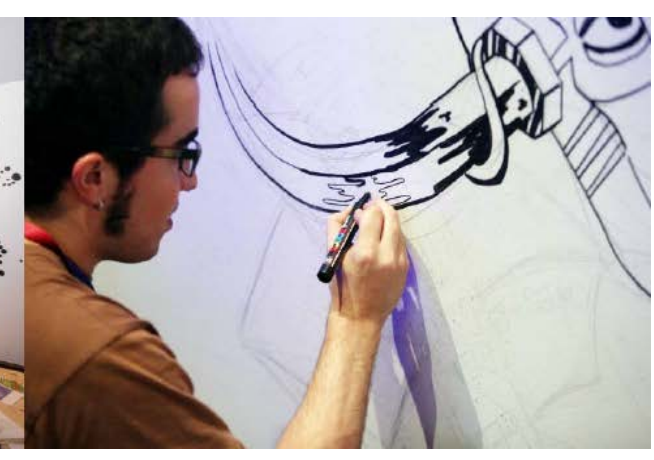

Figure 2. a.b. "Living wall". Traslating ideas into drawings, large sketches

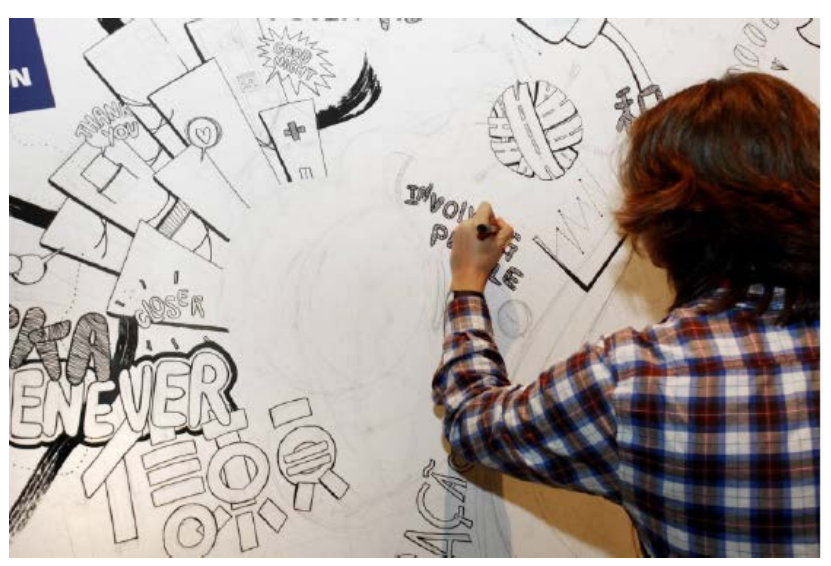

Figure 3. "Living wall". Adding of Lettering 


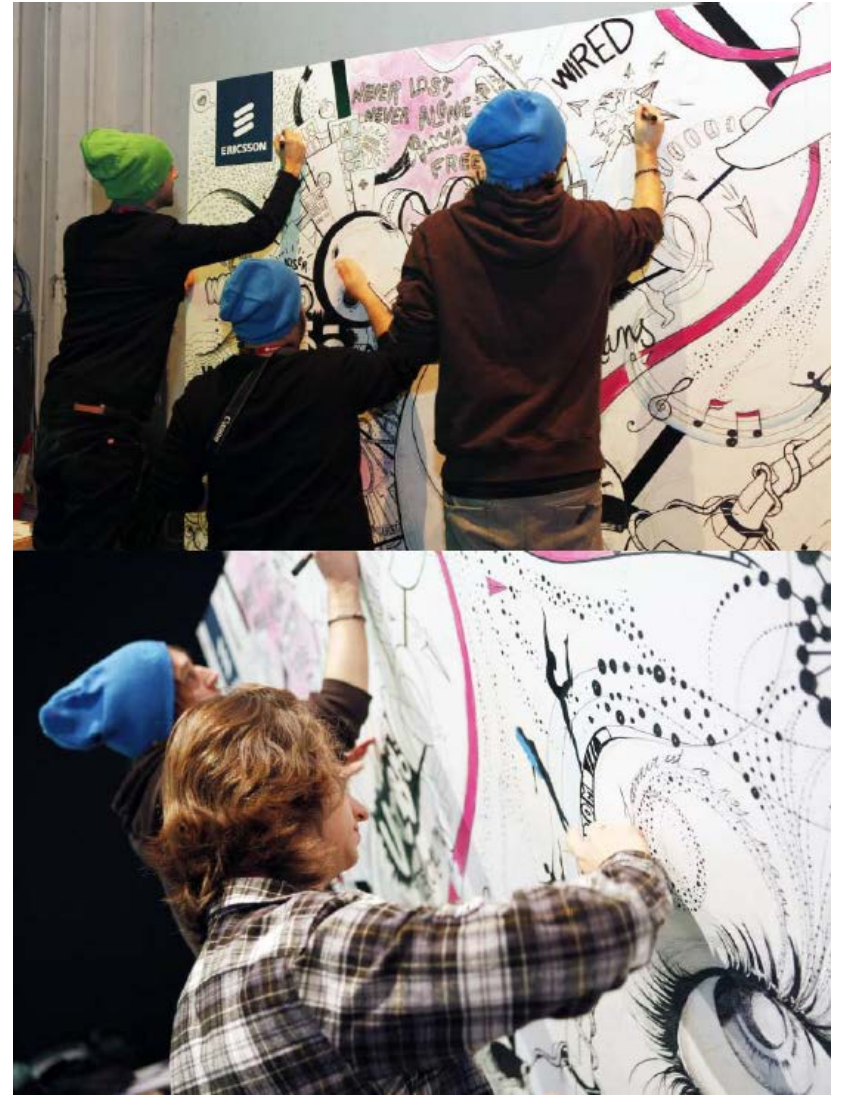

Figure 4. a,b. "Living wall". Adding of color

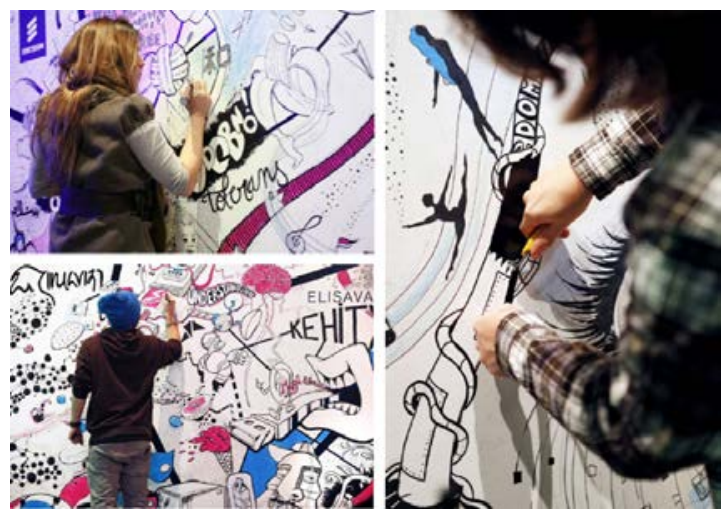

Figure 5. a.b.c. "Living wall". Adding of details

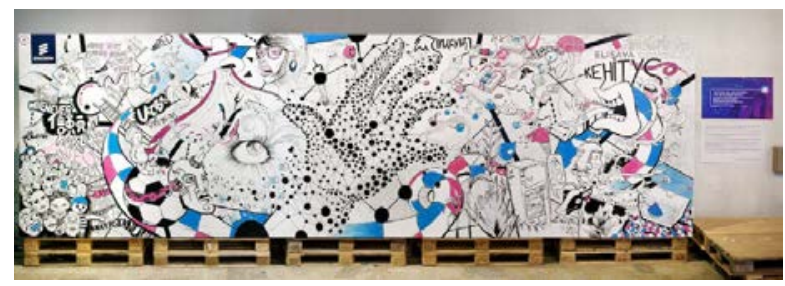

Figure 6. "Living wall". Final work

\subsection{Case Study 2}

The "ELISAVA in 4 walls" mural is the result of one of the 17 workshops undertaken during the 13th edition of the ELISAVA Creative Marathon which took place from December 17th-20th, 2012.

The goal of this exercise was to transform the School's interior through vinyl pieces that would alter space perception and interaction with users.

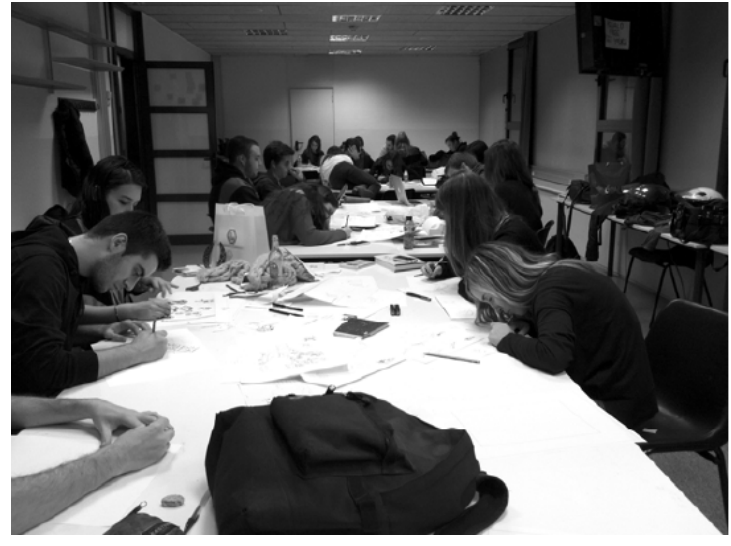

Figure 7. "ELISAVA in 4 walls"
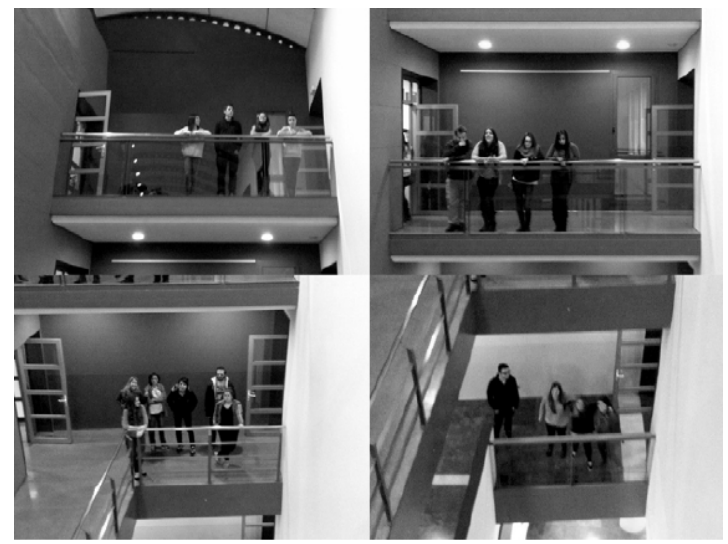

Figure 8. "ELISAVA in 4 walls". The four teams, one per floor

Twenty-two third- and fourth-year Design and Engineering Degree students from various backgrounds conceptually developed the idea for the project during a first phase over three days (e.g. Figure 7). A tutor/professor - Ivan Bravo - coordinated the group, which had been split into four teams assigned to each floor (e.g. Figure 8). Later, in a two-month second phase, two Design Degree students and two junior designers (ELISAVA alumni) defined the design and final art, including a colour study and the digitisation of all handsketched drawings. Finally, the vinyl banners were printed and set up with help from MACTAC, a specialised company.

The main challenge was to propose a creative collaboration situation to students from different backgrounds, from the Design and Engineering programs, in order to create a single illustration.

For the ELISAVA community, the most important contribution was that students took over the space and decided to freely tell their own story. The initial briefing was very open. From the school side, we just wanted them to give free expression to their creativity, and we had asked them to "tell a story" on these four walls. We wanted them to ensure the autonomy of each illustration/floor and at the same time the continuity between floors. It could have been the story of a growing tree or animals climbing the walls.

The second challenge was the timing of the first phase (four days) and the size of the surface to be covered (approximately 18 square metres per floor for a total of 80 square metres).

What was most important was finding an advisor who had previous experience with graphic projects applied to 
large-scale space, and who could steer the ideas of 22 students with the skills of an orchestra conductor.

The project was divided into three main stages:

1. Brainstorming and concept generation, during the four workshop days in December 2012 (e.g. Figure 9a, 9b, 9c, 9d)

2. Developing sketches and layout of the final art mural (January - February 2013) (e.g. Figure 10a, 10b, 10c)

3. Vinyl production and placement (March - April 2013) (e.g. Figure 11a, 11b, 11c)

Each one of the floors depicts the experience of our students throughout each of the academic courses. Four courses depicted in four floors: emblematic exercises, anecdotes, inquisitiveness, fears, tensions, order, disorder, expectations, efforts, and a lot of coffee, an element that, curiously enough, is present in every floor. To enhance the relationship between floors, we included details that connect the floors bottom-up conceptually and physically giving it a reading orientation consistent with the concept of growth and evolution to be expected from a university career.
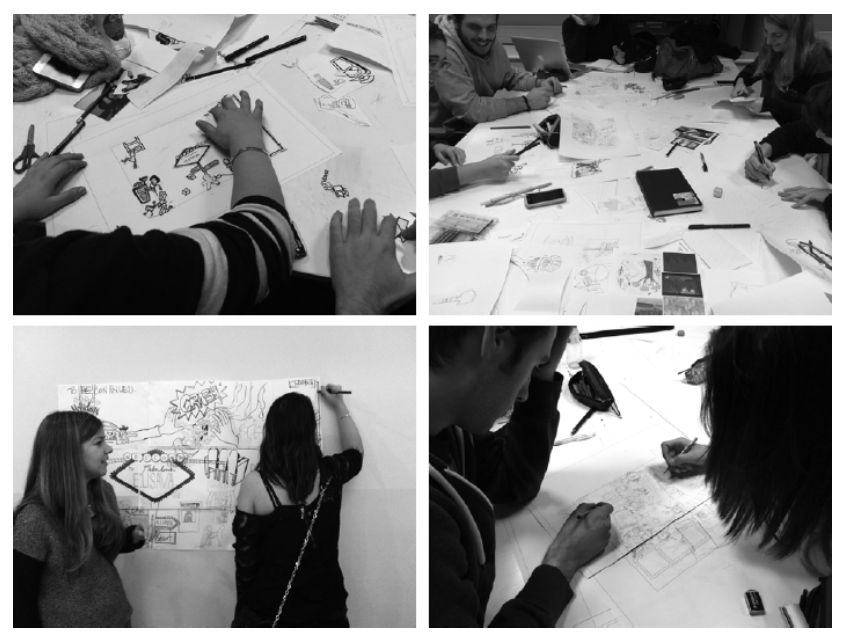

Figure 9. a,b,c,d. "ELISAVA in 4 walls". Sessions of brainstorming and concept generation
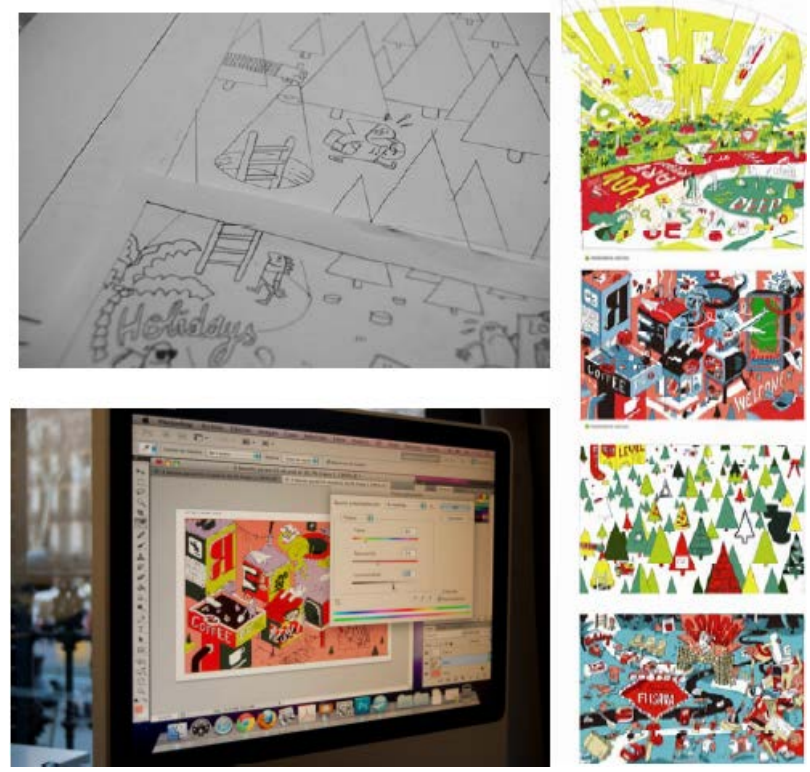

Figure 10. a.b.c. "ELISAVA in 4 walls". Developing analog and digital sketches and layout of the final art mural

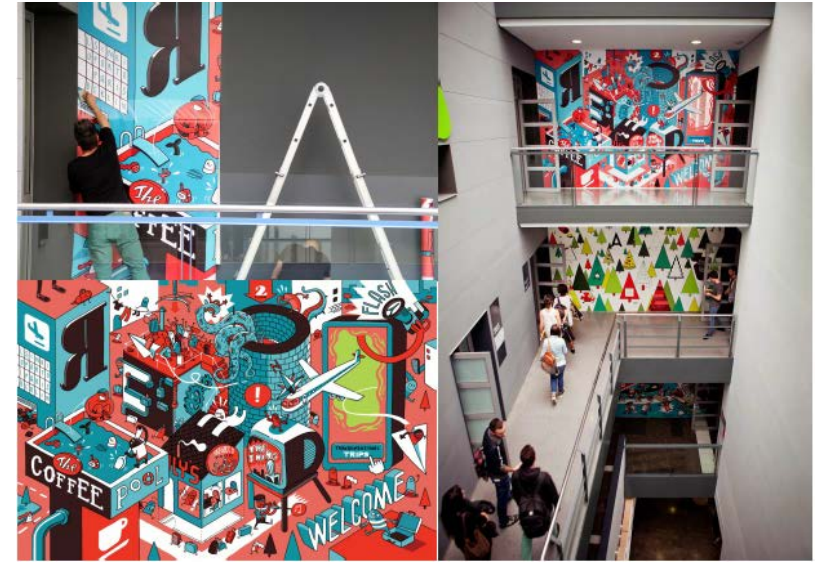

Figure 11. a.b.c. "ELISAVA in 4 walls". Vinyl production and placement

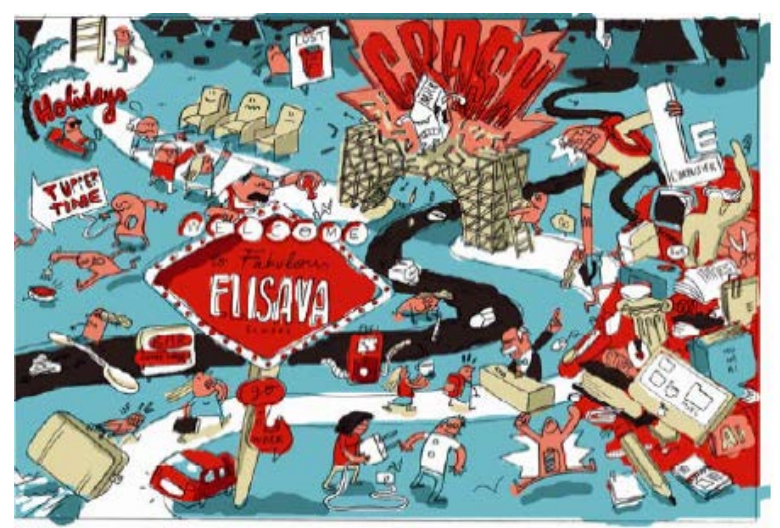

Figure 12. "ELISAVA in 4 walls". Final art of the first floor

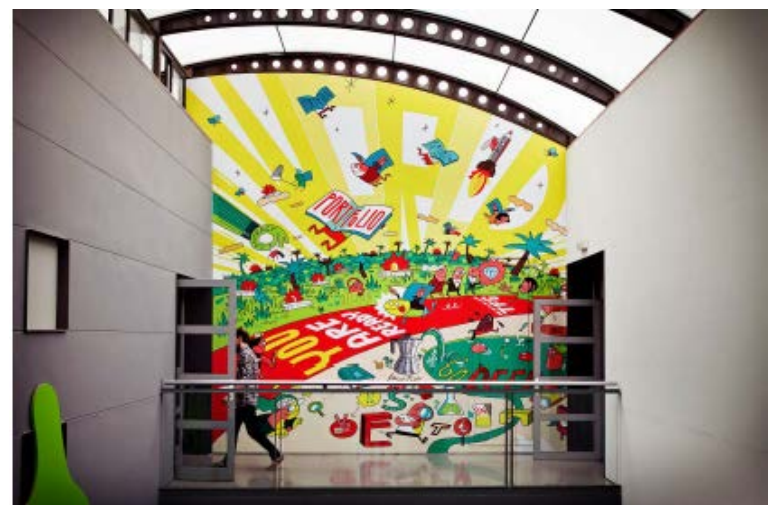

Figure 13. "ELISAVA in 4 walls". Final art of the fourth floor

The first floor/course is the beginning of a journey where we discover there is a lot to do (e.g. Figure 12). The second floor/course is a labyrinth-forest where we feel lost in front of the multiple options to choose from. The third floor/course is the moment to specialise and travel to study abroad. The fourth floor/course is the moment to focus on the final degree project and launch our professional future (e.g. Figure 13). Lastly, each mural is a diary page where students can see themselves projected in the future, reflected in the present and remembered in the past.

\section{Conclusions}

Seeing their work of collective authorship every day at school gives students great satisfaction, and for first-year 
students, it is a "dream" to think of being able to do something similar in the future.

The project has greatly exceeded everyone's expectations, even the school management's, who at first had only given us authorisation to use those walls for six months. A year later, it is still there and has become an iconic image of the school.

The challenges in both the first and second case were:

1. To practice collective creativity models removed from existing preconceptions, to create a single illustration.

2. To apply creativity and imagination, encouraging thinking outside the box.

3. To propose a creative collaboration situation to students in order to create a big illustration - in the first case with an objective public and in the second case between students from different backgrounds.

4. To create within time constraints - in the first case in real time, and in second case with a bit more time.

These case studies show that when students are in their third or fourth year at the university, their academic maturity enables them to resolve collective creativity projects more readily and with better group dynamics.

\section{Acknowledgement}

Special thanks to students, and tutors Chema Longobardo and Ivan Bravo for guiding team's creativity.

\section{References}

[1] Findeli, A., "Rethinking design education for the 21st century: theoretical, methodological and ethical discussion”, Design Issues 17 (1): 5-17, 2001.

[2] De Bono, E., Lateral thinking, Pelican Books, London, 1991.

[3] Robinson, K. Out of our minds: Learning to be creative, Wiley India (P) Ltd., New Delhi, 2001.

[4] Kolb, D. A., Experiential Learning: experience as the source of learning and development. Prentice Hall, Englewood Cliffs, NJ, 1984.

[5] Wolff, C., Psychologia empirica, 1730.

[6] Rodari, G., Grammatica della fantasia. Giulio Einaudi, Turin, 1973.

[7] M.A. Boden, The creative mind. Myths and mechanism. 2nd edition. Routledge, London and New York, 2004, p. 1.

[8] Munari, B. Fantasia. Bari: Laterza. 1977.

[9] Bolullo, R. La conexión creadora. Barcelona: Ediciones Gestión 2000, 2013. 